\title{
GENEALOGÍA DEL CONSTITUCIONALISMO DEMOCRÁTICO EN CHILE: EL TRABAJO DEL GRUPO DE LOS 24 EN LAS PROPUESTAS DE CAMBIO CONSTITUCIONAL
}

DRA. TANIA BUSCH VENTHUR DR. MANUEL CAMPOS DÍAZ 
SUMARIO

1. INTRODUCCIÓN. 2. UNA PROPUESTA DE PERIODIFICACIÓN DEL PROCESO CONSTITUYENTE CHILENO. 3. EL GRUPO DE ESTUDIOS CONSTITUCIONALES Y SUS PRINCIPALES IDEAS. 4. IDEAS DEL GRUPO DE LOS 24 RECOGIDAS EN CAMBIOS LEGISLATIVOS O CONSTITUCIONALES DURANTE LA VIGENCIA DE LA CONSTITUCIÓN DE 1980. 4.1.- Modernización del Poder Judicial y administración de justicia. 4.2.-Partidos políticos y sistema electoral. 4.3.- Tribunal Constitucional. 4.4.- Otras propuestas incorporadas al ordenamiento jurídico chileno. 5. PROPUESTAS PARA UNA NUEVA CONSTITUCIÓN Y EL IDEARIO DEL GRUPO DE ESTUDIOS CONSTITUCIONALES. 5.1-. Rol del Estado, Estado social y democrático de derecho y derechos sociales. 5.2-. Igualdad sustantiva y grupos desaventajados. 5.3.-Necesidad de modificar la forma de gobierno, señalando dos alternativas posibles, la consagración de un régimen presidencial atenuado, o el establecimiento de un sistema semipresidencial de gobierno. 5.4.- Descentralización y Estado Regional. 5.5-. Aumento de la legitimidad democrática de la jurisdicción constitucional y modificación de sus atribuciones. 5.6-. Cláusula de recepción del Derecho Internacional de los Derechos Humanos. 5.7-. Necesidad de modificar el estatuto constitucional de las Fuerzas Armadas y reforzar su subordinación al poder civil. 6. CONCLUSIONES. 


\title{
GENEALOGÍA DEL CONSTITUCIONALISMO DEMOCRÁTICO EN CHILE: EL TRABAJO DEL GRUPO DE LOS 24 EN LAS PROPUESTAS DE CAMBIO CONSTITUCIONAL ${ }^{1}$
}

\author{
DRA. TANIA BUSCH VENTHUR ${ }^{2}$ \\ DR. MANUEL CAMPOS DÍAZ ${ }^{3}$
}

\section{INTRODUCCIÓN}

Pisarello define un proceso constituyente como el «conjunto de actos que conducen a la aprobación de una nueva Constitución» ${ }^{4}$. Así, la expresión incluye los antecedentes políticos, sociales e intelectuales que hacen necesario, explican y desembocan en un cambio constitucional. El cambio constitucional, por el contrario, se acota al proceso institucional a través del cual se reforma o reemplaza una Constitución.

1 Una primera versión de este trabajo se presentó en el seminario «Manuel Sanhueza revisitado: una recuperación del discurso del Grupo de los 24 para el debate constitucional actual» organizado por la Facultad de Ciencias Jurídicas y Sociales de la Universidad de Concepción, el 25 de junio de 2015. Debemos gran parte de las fuentes consultadas en esta investigación a doña Gabriela Jara, viuda de Manuel Sanhueza, quien nos entregó en su oportunidad documentos personales del Presidente del Grupo de los 24, manuscritos y recortes de prensa sin los cuales esta investigación no habría sido posible. Le estamos profundamente agradecidos por su generosidad y a su memoria dedicamos este trabajo.

2 Abogada, Licenciada en Ciencias Jurídicas y Sociales por la Universidad de Concepción. Magíster en Ciencias Jurídicas y Doctora en Derecho por la Pontificia Universidad Católica de Chile. Profesora Asistente, Área de Derecho Público, Universidad Andres Bello. Facultad de Derecho. Bellavista 0121, Providencia, Santiago de Chile. Chile. ORCID 0000-0002-6943-2595.tania.busch@unab.cl.

Abogado, Licenciado en Ciencias Jurídicas y Sociales por la Universidad Concepción. Doctor en Derecho por la Universidad de Chile. Profesor Asistente Departamento de Historia y Filosofía del Derecho, Facultad de Ciencias Jurídicas y Sociales, Universidad de Concepción. manucamp@udec.cl. El autor agradece al fondo de incentivo para publicaciones de la Facultad de Ciencias Jurídicas y Sociales de la Universidad de Concepción.

4 PISARELLO, G. (2014). Procesos constituyentes. Caminos para la ruptura democrática, Madrid, Trotta. 
Sostenemos que el proceso constituyente chileno se instaló hace ya décadas en la discusión política y académica; y, desde 2011 en adelante, en la discusión ciudadana. Luego de la reforma constitucional posterior al «Acuerdo por la Paz y la Nueva Constitución», nos encontramos en un proceso regulado de cambio constitucional que deberá conducir a la aprobación de una nueva Constitución.

Aunque la efervescencia de la demanda constitucional aumentó durante la última década, el problema constitucional dista de ser nuevo. El cauce de este problema en la doctrina constitucional chilena se ha estructurado en tres ejes fundamentales de crítica, que permanecen desde antes de la vigencia de la Carta hasta hoy: su origen autoritario que impide considerarla legítima; segundo, el establecimiento de un sistema democráticamente deficitario; y tercero, la opción ideológica de la Constitución por una concepción neoliberal y como consecuencia de esto, una débil consagración de los derechos económicos y sociales. ${ }^{5}$ Esas líneas críticas permanecen hasta nuestros días ${ }^{6}$. Así se observa al contrastar las críticas desarrolladas, con lo planteado el año 1981 por el Grupo de Estudios Constitucionales, conocido también como «Grupo de los 24». Un día antes de que comenzara a regir la Constitución de 1980, publicó un documento que contenía las principales críticas a la carta. Este comenzaba declarando que «...la nueva Constitución rechaza el sistema representativo de gobierno, desconoce el derecho natural y exclusivo del pueblo para gobernarse, niega el pluralismo ideológico, establece un régimen político autoritario-militarista, implanta un verdadero cesarismo presidencial, minimiza al Parlamento, transforma al Tribunal Constitucional en un organismo burocrático carente de representatividad popular y más poderoso que el Congreso, otorga un poder ilimitado a las FF.AA., subordina la vigencia de los derechos humanos fundamentales al arbitrio del gobierno y se identifica en lo económico con el capitalismo individualista de libre mercado. Además, dadas las exigencias que impone para eventuales reformas constitucionales, perpetúa un determinado régimen político, económico y social, que resulta prácticamente imposible de modificar» ${ }^{7}$. Del contraste de las críticas que hoy se formulan a la carta vigente, con las enunciadas el año 1981, se observa que las críticas a la Constitución de 1980 han corrido por los mismos ejes durante las últimas cuatro décadas, y que los constitucionalistas demócratas no

5 BUSCH, T. (2012). El concepto de Constitución y la incomodidad constitucional en Chile. Global jurist 12 (2), Doi: 10.1515/1934-2640.1410.

6 Gajardo adhiere y agrega como críticas la visión monocultural y nacional de la Constitución, en la cual no se reconoce el carácter multicultural de la sociedad chilena y, en particular, a los pueblos indígenas; el excesivo centralismo territorial; y el híper presidencialismo y el fenómeno de la concentración del poder. GAJARDO, J. (2015) «El dilema constitucional chileno» Serie Documentos de Trabajo ${ }^{\circ}$ 15, Universidad Externado de Colombia. Disponible en https://icrp.uexternado.edu.co/sdm_downloads/15-el-dilema-constitucional-chileno-jaime-gajardo-falcon/p.5

GRUPO DE ESTUDIOS CONSTITUCIONALES (1988). «Las Críticas del Grupo de los 24», Revista APSI (N²76 Año XIII, octubre - noviembre), p. 32 
erraban cuando sostuvieron que esta impedía «cualquier evolución política, económica y social profunda dentro de sus marcos»"8.

La literatura reciente no parece advertir que los antecedentes de la crítica al proyecto constitucional autoritario se remontan al comienzo de la redacción de la Constitución de 1980. En general, los académicos promotores del cambio constitucional no se identifican como continuadores de la generación de constitucionalistas que resistieron al constitucionalismo autoritario en las horas más oscuras. Para encontrar antecedentes de constitucionalismo democrático y republicano acuden al período previo al golpe de Estado, específicamente a las normas constitucionales de la Constitución de 1925 y al trabajo doctrinario realizado sobre la misma9.

No vemos problema en excluir del curso constitucional republicano los períodos dictatoriales, mientras se reconozca que hubo quienes, durante los paréntesis autoritarios, mantuvieron y transmitieron las concepciones republicanas y democráticas que hicieron posible recuperar la República. Coincidimos con Ruiz-Tagle ${ }^{10}$, para quien el desarrollo histórico constitucional chileno representa un curso evolutivo fundado en principios republicanos, democráticos y liberales, y propone una taxonomía constitucional que divide nuestra historia republicana en cinco repúblicas, cada una de ella marcada por momentos constitucionales que considera como definitorios (la Constitución de 1828, las reformas liberales a la Constitución de 1833, la puesta en vigencia de la Constitución 1925); excluyendo de dicha evolución constitucional al periodo comprendido entre 1973 y 1990, comenzando a partir de este año la República neoliberal.

Este trabajo pretende revalorizar la labor del Grupo de Estudios Constitucionales (en adelante Grupo de los 24, o simplemente el Grupo) que constituyó un bastión de principios democráticos y republicanos durante la dictadura cívico-militar y que sirve de nexo entre el constitucionalismo previo a la dictadura y la tradición constitucional que continuará tras el retorno a la democracia, constituyéndose una genealogía que vincula el constitucionalismo democrático chileno de las repúblicas ${ }^{11}$. Así, esta propuesta puede complementar la periodificación de Ruiz-Tagle, permitiendo comprender los vínculos que retoman y dan continuidad al curso republicano. Así lo intuyó el mismo Grupo cuando en el año 1992 señalaba «[m]uchos personeros, incluso del

8 GRUPO DE ESTUDIOS CONSTITUCIONALES (1988). «Las Críticas del Grupo de los 24», Revista APSI (N²76 Año XIII, octubre - noviembre), p. 32.

9 Trabajos como el de MUÑOZ (2016) no sólo excluyen el trabajo del Grupo de los 24, sino que lo consideran como el primer paso de un acuerdo transicional entre la Junta Militar y Patricio Aylwin. Para ello, basándose en algunos párrafos de la autobiografía del ex-presidente y miembro fundador del grupo, cuestionan el carácter pluralista del mismo y las convicciones democráticas de sus miembros, las que señala habrían quedado «a criterio del propio Aylwin». p.125 y sgtes.

10 RUIZ- TAGLE, P. (2006). «El constitucionalismo chileno: entre el autoritarismo y la democracia», en R. Cristi y P. Ruiz-Tagle, La República en Chile. Teoría y Práctica del Constitucionalismo Republicano. pp. 79-143, Santiago, LOM, p. 79 y sgtes.

11 El concepto de constitucionalismo democrático, en oposición al constitucionalismo antidemocrático o autoritario lo tomamos de Pisarello (2011). 
más alto nivel del régimen militar autoritario, se equivocaron al ignorar, menospreciar y tratar de silenciar al Grupo. No percibieron que las ideas, el intercambio de opiniones, la discusión razonada, serena y éticamente orientada, siempre rinde frutos y prevalece sobre la fuerza, por poderosa y organizada que ésta sea, por prolongado que sea su reinado» ${ }^{12}$.

Entendemos por genealogía constitucional el vínculo existente entre la doctrina constitucional intergeneracional. Es decir, que las ideas que presentan los académicos y académicas en el debate constitucional chileno surgen a partir de propuestas y trabajos previos de otros cultores del derecho constitucional nacional, aunque los primeros no necesariamente sean conscientes de esta conexión. Con esto queremos decir que las propuestas del debate constitucional actual, en su mayoría, no aparecen como una «exportación» de conceptos foráneos. Aunque puedan haberse enriquecido con literatura extranjera o modelos comparados, su núcleo ya se encontraba presente desde sus inicios en la crítica demócrata al proyecto constitucional autoritario.

En este trabajo demostraremos que las propuestas que hoy se presentan como imprescindibles de ser abordadas en una nueva Constitución en muchos casos pueden reconducirse a las propuestas del Grupo de los 24, y que, por lo tanto, existe una continuidad entre sus postulados y el cambio constitucional actual. Con este objetivo (I) propondremos una periodificación del proceso constituyente chileno; (II) describiremos brevemente el surgimiento del Grupo de los 24 y explicaremos su trabajo y principales ideas; (III) expondremos cómo sus ideas fueron recogidas en diversos cambios legislativos o constitucionales introducidos durante la vigencia de la Constitución de 1980 que fortalecieron el régimen democrático y morigeraron la ilegitimidad inicial de la Constitución; y (IV) desarrollaremos algunas de las propuestas del Grupo que hoy son contenidos ineludibles en la discusión sobre contenidos de la nueva Constitución.

\section{UNA PROPUESTA DE PERIODIFICACIÓN DEL PROCESO CONSTITUYENTE CHILENO}

Los procesos constituyentes suelen verse como eventos extraordinarios, que interrumpen periodos prolongados de conformidad con el orden constitucional. Esto no ha sido así en América Latina, y tampoco en Chile. Lejos de ser un acontecimiento extraordinario y disruptivo de la normalidad constitucional, el proceso constituyente chileno acompaña toda la vigencia de la Constitución de 1980, e incluso, se inicia junto con la creación de ésta. Como es sabido, la Constitución de 1980 se prepara por un grupo de juristas más o menos partidarios de la dictadura, que sesionan desde 1973 en adelante en una Comisión de Estudios para una Nueva Constitución conocida por su sigla CENC o «Comisión Ortúzar». Desde ese minuto, constitucionalistas y políticos

12 GRUPO DE ESTUDIOS CONSTITUCIONALES (1992) p.283. 
opusieron resistencia al proyecto constitucional autoritario, alzándose voces disidentes que lo analizaron, discutieron y presentaron propuestas alternativas.

La opción de transición que tomó Chile, de mantener la Constitución de 1980, aunque reformada, tuvo como costo que ésta nunca pudiera ser apropiada por el pueblo. Siempre mantuvimos una incomodidad constitucional ${ }^{13}$, que con el tiempo fue incrementándose. Este antecedente necesariamente debe considerarse. La prolongada gestación del cambio constitucional explica por qué la demanda no irrumpe de la mano de un liderazgo identificable, como ha sido en otros procesos latinoamericanos recientes. Al contrario, se ha ido progresivamente sedimentando en la comunidad política. La necesidad de una asamblea constituyente se plantea durante la década de $1980^{14}$, y ciertamente entre 1990 y 2002, en que se funda el Movimiento por la Asamblea Constituyente ${ }^{15}$. Muestra de ello es que el día 9 de septiembre de 1980, previo al plebiscito convocado por la dictadura para ratificar la Constitución de $1980^{16}$, el Grupo de los 24 en su declaración «Compromiso por la Democracia» llama a convocar «a una Asamblea Constituyente de elección popular, que elabore con participación de todos una nueva Constitución Política, que se someta a la aprobación del pueblo» ${ }^{17}$.

Para comprender la profundidad y antecedentes del proceso, proponemos los siguientes periodos o etapas del proceso constituyente chileno:

- La primera etapa se manifiesta en la resistencia al proyecto constitucional de la dictadura. En esta resulta fundamental la crítica que el Grupo de los 24 realizó durante la elaboración y el primer período de vigencia de la Constitución de 1980.

- Hemos denominado a la segunda etapa como de la resignación. Se inicia con la reforma constitucional de año 1989 y contempla las diferentes reformas a la Constitución hasta el año 2010, siendo particularmente importante la reforma constitucional del año $2005^{18}$. Se persigue terminar progresivamente con los enclaves autoritarios por la vía del poder constituyente derivado. Durante esta etapa las élites intelectuales van a instalar la necesidad de una

13 BUSCH VENTHUR, T. (2012). El Concepto de Constitución y la Incomodidad Constitucional en Chile. Global Jurist 12 (2). Doi: 10.1515/1934-2640.1410.

14 GRUPO DE ESTUDIOS CONSTITUCIONALES (1980)

15 PALMA GONZÁLEZ, Eric Eduardo (2015) «36 años demandando Asamblea Constituyente (1979-2015).» En FERNÁNDEZ GAETE, Manuel y FIGUEROA CLAUDE, Cristián (Editores) «Fumando Opio. De la Asamblea Constituyente al Poder Ciudadano», Santiago, Academia de Humanismo Cristiano y Mutante Editores, p. 142.

16 Este plebiscito no tuvo legitimidad, realizándose sin registros electorales ni garantías mínimas. Ver FUENTES (2013)

17 GRUPO DE ESTUDIOS CONSTITUCIONALES (1980)

18 Para una descripción general del desarrollo de la vigencia de la Constitución de 1980, ver Palma (2007), Heiss y Szmulewicz (2018). 
nueva Constitución, mientras los actores políticos seguirán apostando por las reformas constitucionales parciales.

- La tercera etapa corresponde a la búsqueda institucional de un cambio constitucional. A comienzos de la década del 2010 se instaló en las campañas presidenciales la necesidad de una nueva Constitución. Sin embargo, con el triunfo en la elección presidencial de Sebastián Piñera, se pierde el impulso constitucional. Coetáneamente, la ciudadanía inicia movilizaciones sociales que comienzan a vincular demandas de satisfacción de derechos sociales con el problema constitucional. Inspirados por el caso colombiano, se crea la agrupación «Marca tu Voto» que trata de replicar la experiencia de la Séptima Papeleta, llamando a marcar el voto con la sigla «AC» ${ }^{19}$ en las elecciones del año 2013. No surtió el mismo efecto, pero lograron instalar definitivamente el problema constitucional en la discusión pública, marcando los debates de las próximas elecciones presidenciales. En éstas resulta electa Michelle Bachelet, quien incluía en su programa de gobierno el inicio de un proceso constituyente «democrático, participativo e institucional». Este intento no prosperó, y fue clausurado con la elección de Sebastián Piñera para su segundo periodo presidencial el año 2017.

- Finalmente, la cuarta etapa corresponde a un proceso de activación del poder constituyente originario, que va a irrumpir catalizado por el estallido social, y que se canaliza por el acuerdo de noviembre de 2019, para resolver de forma institucional el problema constitucional ${ }^{20}$.

Incluir estas etapas en la duración del proceso constituyente permiten integrar a éste el profundo proceso de reflexión que ha existido a su respecto. No sólo la extensa producción académica generada respecto de los contenidos de la Constitución de 1980 y propuestas para un nuevo texto, sino también ejercicios participativos y deliberativos como el movimiento «Marca tu Voto» e iniciativas de participación y deliberación institucionales como los Encuentros Locales Autoconvocados, que precedieron el intento de cambio constitucional de la presidenta Bachelet. En estos se discutió colectivamente en torno a valores y principios; derechos, deberes y responsabilidades; e instituciones del Estado que debería incorporarse en la nueva Constitución $^{21}$. El proyecto enviado por Bachelet al Congreso Nacional nunca fue discutido,

19 Por Asamblea Constituyente.

20 Estamos conscientes que la caracterización del proceso de cambio constitucional en que nos encontramos como ejercicio del poder constituyente originario ha sido controvertida por algunos, toda vez que se concreta en una reforma constitucional que lo regula. También estamos conscientes de que la distinción entre poder constituyente originario y derivado puede no ser del todo útil hoy para explicar los fenómenos. Sin embargo, dejaremos la profundización de estos conceptos para otra investigación.

21 Ver SOTO y WELP (2017). La sistematización de esta reflexión colectiva se puede revisar en http://archivospresidenciales.archivonacional.cl/index.php/encuentros-locales-autoconvocados-con-sistematizacion-de-fundamentos-valores-y-principios 
y es fallido como cambio constitucional, pero exitoso como ejercicio deliberativo. Sin esta reflexión colectiva previa, la ciudadanía no habría tomado conciencia de la dimensión constitucional de las demandas sociales.

Conforme a lo expuesto, el estallido social de octubre de 2019 no da inicio al proceso constituyente, sino que actúa como el catalizador que permitió entender que la Constitución de 1980 constituye un factor de inestabilidad y división que erosiona la legitimidad de las instituciones que establece. Esto quedó patentemente demostrado con los resultados del plebiscito de octubre de $2020^{22}$.

\section{EL GRUPO DE ESTUDIOS CONSTITUCIONALES Y SUS PRINCIPALES IDEAS}

El Grupo de los 24 surge como un esfuerzo concertado y pluralista para estudiar y «ofrecer al pueblo de Chile una alternativa de organización política democrática, que respete la tradición institucional chilena, la perfeccione y adecúe a las modalidades que han emergido en la sociedad contemporánea» ${ }^{23}$. Su «acta de nacimiento» es el documento publicado en el diario «El Mercurio» el 21 de julio de 1978, en que llaman a la creación de un grupo plural que se centraría en el debate de propuestas para dotar a Chile de una nueva y mejorada institucionalidad republicana y democrática, en contraposición al proyecto constitucional de la Junta Militar ${ }^{24}$. El documento fue suscrito por veinticuatro personalidades que darán nombre a la agrupación: René Abeliuk, Patricio Aylwin, Edgardo Boeninger, Fernando Castillo Velasco, Jaime Castillo, Héctor Correa, Gonzalo Figueroa, Juan Agustín Figueroa, Ignacio González, Luis Izquierdo, Eduardo Jara, Eduardo Long, Joaquín Luco, Luis Fernando Luengo, Alberto Naudón, Hugo Pereira, Raúl Rettig, Pedro Rodríguez, Manuel Sanhueza, quien lo presidirá; Víctor Santa Cruz, Alejandro Silva Bascuñán, Ramon Silva, Julio Subercaseaux y Sergio Villalobos ${ }^{25}$. Todos sus integrantes eran opositores a la dictadura, aunque provenían de diversas posiciones políticas $^{26}$. Su integración transversal buscaba presentarse a la ciudadanía

22 En el plebiscito de octubre de 2020 la pregunta «¿Quiere usted una Nueva Constitución?» la opción «Apruebo» obtuvo un 78,28\% de los sufragios, mientras que el «rechazo» obtuvo apenas 21,72\%. (información disponible en https://pv.servelelecciones.cl/).

23 GRUPO DE ESTUDIOS CONSTITUCIONALES (1992) p.1.

24 Sobre el origen del Grupo de Estudios Constitucionales ver: Quinzio (2002) p. 15.

25 Si bien este es el momento de nacimiento del Grupo de los 24, un antecedente para el surgimiento del mismo se encuentra en las reuniones mensuales convocadas por el Padre Jesuita Mario Zañartu a diversas personalidades con el objeto de intercambiar ideas sobre la propuesta constitucional que estaba siendo elaborada por la dictadura militar. Para más antecedentes sobre este punto puede consultarse SANHUEZA (2001) p. 49 y sgts.

26 Algunos se identificaban con la Democracia Cristiana, Partido Radical y otros partidos de centroizquierda.

(C) UNED. Revista de Derecho Politico

N. ${ }^{\circ} 112$, septiembre-diciembre 2021, págs. 355-382 
como actores independientes quienes, más allá de sus militancias políticas, actuaban con sentido de deber cívico y republicano ${ }^{27}$.

Durante el periodo autoritario el grupo desarrolló una reflexión sistemática sobre las instituciones políticas fundamentales y el diseño de un sistema constitucional que permitiera la vigencia efectiva de los derechos fundamentales y una democracia sustantiva. El trabajo se centró, en una primera etapa, en criticar el trabajo constitucional de la Junta de Militar y en elaborar una propuesta constitucional republicana y democrática para Chile. Dicha labor se estructuró en comisiones temáticas en la que participaron finalmente unas 3.000 personas del espectro político y social opositor al gobierno de la Junta Militar ${ }^{28}$. Sus actividades se iniciaron con la creación del grupo, en julio de 1978 y culminaron con acuerdos unánimes en 1979. Una síntesis de estas propuestas se presentó en el documento denominado «Bases Fundamentales de la Reforma Constitucional» de octubre de 1979. En este se afirmaba que no era necesaria una nueva Constitución, bastando algunas reformas a la Carta de 1925; la necesidad de que el Congreso Nacional fuera electo por votación popular y que no solo tuviera una función legislativa, sino también de control y fiscalización; consideraban a los partidos políticos como esenciales para la democracia, y proponían robustecer la representatividad del Tribunal Constitucional, entre otras materias.

Ya vigente la Constitución de 1980, el grupo centrará sus esfuerzos en retomar un régimen democrático, proponiendo cambios a la carta otorgada. La obra «Las Propuestas Democráticas del Grupo de los 24», publicada en 1992, sintetiza las ideas de 14 años de trabajo para el establecimiento de un régimen republicano y democrático en Chile ${ }^{29}$, que en gran medida fueron recogidas por las reformas constitucionales de 1989 y 2005 . Las principales propuestas pueden sintetizarse en las siguientes:

- El régimen democrático es el único compatible con la tradición histórica de Chile $^{30}$. Este debe fundarse en los principios de Estado de derecho, separación de los poderes públicos, generación periódica de los gobernantes por elecciones populares a través de sufragio universal, libre, secreto, personal,

27 BELTRAN (2018). p. 8

28 Resulta imposible identificar a todos los abogados y abogadas que participaron en el Grupo de Estudios Constitucionales. Asumiendo omisiones queremos destacar especialmente la participación de Adolfo Veloso, Augusto Parra, Eduardo de la Barra, Francisco Cumplido, Francisco Tapia, Francisco Zúñiga, Francisco Huenchumilla, Humberto Nogueira, Jorge Correa Sutil, Jorge Mario Quinzio, Lautaro Ríos, Roberto Garretón, Mariano Ruiz Esquide, Mario Verdugo, Radomiro Tomic y René Safirio. El listado completo se puede consultar en GRUPO DE ESTUDIOS CONSTITUCIONALES (1992). Nombraremos expresamente a todas las mujeres que participaron del Grupo: Adriana Soto, Berta Belmar, Carmen Garrido, Dora Silva, Ester Farías, Georgina Leiro, Georgina Valenzuela, Iris Contreras, Hilda Bustos, Hilda Valderrama, Laura Soto, Luisa Andrade, Magaly Huerta, María Isabel Norero, María Gaona, María Elisa Hurtado, María Maldascky Nelly Villanueva, Carmen Fuentes, Matilde Chonchol, Mónica Weisner, Olga Mercado, Paula Correa, Paulina Veloso, Sandra González, Wilna Saavedra.

29 GRUPO DE ESTUDIOS CONSTITUCIONALES (1992)

30 GRUPO DE ESTUDIOS CONSTITUCIONALES (1992) P. 49. 
igual e informado; participación y organizada del pueblo en la vida política, social, económica y cultural de la nación; responsabilidad de los gobernantes y publicidad de su gestión, ${ }^{31}$ reconocimiento y garantía de los derechos del hombre y pluralismo ${ }^{32}$.

- El reconocimiento de la soberanía popular ${ }^{33}$ y al pueblo como único titular del poder constituyente. Sostenían que el proceso de generación de una nueva Constitución debía darse en un régimen de plena vigencia de los derechos fundamentales. El proyecto debería estudiarse y debatirse públicamente, por una asamblea constituyente ampliamente representativa y sería el pueblo el llamado a pronunciarse sobre las diversas alternativas que surjan de dicho debate, a través del sufragio universal, libre y secreto, con garantías de transparencia de los registros electorales y corrección de los escrutinios ${ }^{34}$.

- Respecto de la forma de gobierno, el Grupo señala dos alternativas posibles. Una es un régimen presidencial, como el de la Constitución de 1925, pero limitando las atribuciones del Presidente de la República. La otra opción es un sistema semi presidencial de gobierno. ${ }^{35}$

- Respecto de la forma jurídica de Estado proponen un sistema regional, en el cual las regiones contarían con autonomía de gobierno, administrativa y financiera, dentro de los términos establecidos por la Constitución ${ }^{36}$. Relacionado con esto, se proponía establecer el deber estatal de "promover la realización efectiva del principio de solidaridad nacional, velando por un desarrollo adecuado y justo de las diversas regiones y comunas que lo integran ${ }^{37}$.

- Sostenían el carácter esencial de los partidos políticos en cuanto constituyen instrumentos esenciales de la vida democrática ${ }^{38}$. Afirman que corresponde a los partidos la representación de la ciudadanía en los órganos políticos, contribuir a la formación de la voluntad democrática y, especialmente, a la generación de los poderes ejecutivo y legislativo. Asimismo, consideraban como valores esenciales «la aceptación de los principios de generación de las autoridades por voluntad popular y su renovación periódica por el mismo medio, la aceptación de las decisiones de la mayoría y el resguardo de los

\footnotetext{
GRUPO DE ESTUDIOS CONSTITUCIONALES (1992) P. 50-51. GRUPO DE ESTUDIOS CONSTITUCIONALES (1992) P. 7 GRUPO DE ESTUDIOS CONSTITUCIONALES (1992) P. 7 GRUPO DE ESTUDIOS CONSTITUCIONALES (1992) P. 51-52 GRUPO DE ESTUDIOS CONSTITUCIONALES (1992) P. 53-54 GRUPO DE ESTUDIOS CONSTITUCIONALES (1992) P. 108.

Artículo 5 del Anteproyecto sobre Descentralización Política Regional. GRUPO DE ESTUDIOS CONSTITUCIONALES (1992) P. 107.

38 GRUPO DE ESTUDIOS CONSTITUCIONALES (1992) P. 58
} 
derechos de la minoría, el respeto por el pluralismo político e ideológico y el rechazo de la violencia armada como método de acción política contrario a los principios democráticos» ${ }^{39}$.

- Respecto del Tribunal Constitucional, proponían modificar su integración con objeto de aumentar su legitimidad democrática, generando una integración por tercios con origen en los poderes ejecutivo, legislativo y judicial. ${ }^{40}$ Igualmente, sostenían la modificación de las competencias del Tribunal Constitucional, limitando su competencia en materia de control preventivo de constitucionalidad de la Ley a vicios de forma y el establecimiento de la declaración de inconstitucionalidad de una Ley cuando ésta ya haya sido declarada inaplicable al menos en tres oportunidades por la Corte Suprema. ${ }^{41}$

- En materia de derechos fundamentales su «Acta de Derechos Humanos» establece un catálogo que reconoce derechos civiles, políticos, económicos sociales, culturales y ambientales ${ }^{42}$. Destaca la propuesta de consagrar a nivel constitucional que «toda persona tiene derecho a un nivel de vida adecuado que le asegure, así como a su familia, la salud, la educación y el bienestar, y en especial, la alimentación suficiente, el vestuario, la vivienda, la asistencia médica y los servicios sociales necesarios para cubrir las necesidades básicas» ${ }^{43}$. También proponen la incorporación al derecho interno de todos los derechos y libertades reconocidos en la Declaración Universal de Derechos Humanos y pactos complementarios ratificados por Chile ${ }^{44}$.

A las anteriores propuestas pueden sumarse otras en materia de Poder Judicial, igualdad salarial entre hombres y mujeres, reconocimiento de las minorías étnicas, necesidad de regulación detallada de los estados de excepción constitucional, entre otras muchas materias. Estos y otros planteamientos serán abordados en los apartados siguientes, que desarrollarán las propuestas del Grupo que han sido incorporadas al orden jurídico chileno durante la vigencia de la Constitución de 1980 o bien han sido propuestas para ser consideradas en la nueva Constitución.

39 GRUPO DE ESTUDIOS CONSTITUCIONALES (1992) P.58.

40 Proyecto relativo a la «Organización y Funcionamiento del Poder Judicial», GRUPO DE ESTUDIOS CONSTITUCIONALES (1992) p. 35.

41 Proyecto relativo a la «Organización y Funcionamiento del Poder Judicial», GRUPO DE ESTUDIOS CONSTITUCIONALES (1992) p. 34.

42 GRUPO DE ESTUDIOS CONSTITUCIONALES (1992) p. 9.

43 Artículo 17 del proyecto de Acta de Derecho Humanos. GRUPO DE ESTUDIOS CONSTITUCIONALES (1992) p. 278.

44 GRUPO DE ESTUDIOS CONSTITUCIONALES (1992) p. 65. 


\section{IDEAS DEL GRUPO DE LOS 24 RECOGIDAS EN CAMBIOS LEGISLATIVOS O CONSTITUCIONALES DURANTE LA VIGENCIA DE LA CONSTITUCIÓN DE 1980}

El trabajo del Grupo de los 24 y su ideario, planteado en documentos como las Bases Constitucionales de la Reforma Constitucional, el Estatuto de los Partidos Políticos, las Bases Constitucionales del Orden Económico, el Acta de Derechos Humanos, entre otros; no sólo fue un importantísimo esfuerzo intelectual, sino que ha sido determinante en la evolución político-constitucional del Chile de la transición hasta hoy. Son numerosas las materias en las se formularon propuestas concretas para modernizar y democratizar el sistema jurídico chileno. Sus propuestas permanecieron como testimoniales durante el período dictatorial, pero una vez recobrada la senda de la democracia, fueron progresivamente incorporadas al orden constitucional y legal. Por ello resulta necesario vincular la periodificación antes propuesta con el trabajo del Grupo de los 24 y como dicho trabajo influye, incluso de manera inconsciente, en las reformas constitucionales realizadas a la Constitución de 1980.

Pese a su relevancia, la labor del Grupo de los 24 no ha sido estudiada desde la Historia Constitucional, y sus reflexiones han sido ignoradas por la doctrina constitucional crítica del texto de 1980. Como ejemplo, Bassa afirma que las opciones políticas y criterios interpretativos sostenidos durante el periodo previo a 1988-1989 deben considerarse totalmente inaplicables ${ }^{45}$. En contexto, la frase parece referirse a los comentaristas favorables al proyecto constitucional autoritario, pero sirve para ilustrar cómo el trabajo de los constitucionalistas demócratas de la época ha sido obviado. Esta invisibilización se explica por diversos factores. Por un lado, el constitucionalismo chileno de los años 90 y primera década del 2000 estuvo marcado por la hegemonía de la doctrina complaciente con el texto de 1980, y los esfuerzos de la doctrina constitucional demócrata se concentraron en develar que su lectura de la Constitución era sólo una de las posibles, buscando instalar conceptos y teorías largamente ausentes de las aulas en las facultades de Derecho, como los aportes del constitucionalismo social, la falacia de la subsidiariedad como mera abstención estatal en materia económica, la legitimidad democrática originaria como presupuesto de todo poder público o el reconocimiento de la igualdad sustancial y los desafíos que representan para el Derecho los grupos desaventajados. Del mismo modo, los trabajos de Derecho Constitucional e Historia Constitucional recientes se concentraron en la ilegitimidad de la Constitución de 1980 y sus falencias. Otro factor, menos evidente, tiene que ver con la participación de parte importante de los miembros del Grupo de los 24 en la transición, especialmente durante los años 90. Esto ha tenido como consecuencia que su aporte como colectivo no haya sido considerado objeto de estudio y

45 BASSA Mercado, Jaime (2008). El Estado Constitucional de Derecho. Efectos sobre la Constitución vigente y los derechos sociales. Santiago, Editorial Lexis Nexis.p. 43 
sólo recientemente valorado en su real dimensión ${ }^{46}$. Las circunstancias particulares de la transición chilena, en que integrantes del grupo cumplieron roles de primer orden, y las valoraciones críticas a dicho periodo, y las trayectorias individuales de los miembros del grupo, influyeron en que su aporte fuese subestimado.

En los párrafos siguientes recogeremos propuestas del Grupo de los 24 y demostraremos cómo fueron posteriormente reconocidas por reformas legales o constitucionales. Debido a la gran cantidad de propuestas formuladas, centraremos nuestro análisis en tres grandes temáticas: modernización del Poder Judicial y administración de justicia; Partidos Políticos y sistema electoral; y Tribunal Constitucional.

\subsection{Modernización del Poder Judicial y administración de justicia}

Parte relevante de los esfuerzos del Grupo se enfocaron en la crisis del sistema judicial «por no ser apto para dispensarle a la sociedad y a cada individuo la seguridad y protección adecuada que les permitan obtener una acción jurisdiccional que acertada y eficazmente logre la vigencia del derecho.» ${ }^{47}$ Resultaba imprescindible crear una institucionalidad que dotara a la judicatura de un poder efectivo, que fuera un verdadero garante del Estado de Derecho. Ello implicaba tanto modificaciones procesales como reformas administrativas, presupuestarias y relativas al sistema de formación y capacitación de los miembros del Poder Judicial.

Una de las primeras propuestas en la materia fue la creación de una escuela judicial, encargada de la preparación inicial de los magistrados y que también interviniera durante la carrera funcionaria en el perfeccionamiento de los funcionarios judiciales ${ }^{48}$. De esta necesidad se hizo cargo la Ley 19.346 de 1994, que crea la Academia Judicial, corporación de derecho público encargada de la formación y capacitación de los jueces y demás funcionarios del Poder Judicial, para el logro e incremento de aquellos conocimientos, habilidades, destrezas y criterios básicos necesarios para el adecuado ejercicio de su función.

También se propuso la modificación del sistema de remuneraciones. Este debía estructurarse sobre bases objetivas, asegurando a los funcionarios remuneraciones coherentes con la importancia y dignidad de sus cargos, equivalentes a las que percibían los funcionarios del Estado para cargos de análoga jerarquía ${ }^{49}$. Esto se concretará en la Ley 19.531 de 1997, que incrementa y reajusta las remuneraciones del Poder Judicial.

También el Grupo de los 24 abordó el acceso a la justicia, con el fin de evitar la marginación judicial de grupos desplazados tradicionalmente de la vía jurisdiccional al carecer de medios para acceder a mecanismos oportunos y eficaces de solución de

\footnotetext{
46 Así lo mencionan CONTRERAS, Pablo y LOVERA, Domingo (2020). La Constitución de Chile, Valencia, Tirant lo Blanch, p. 40.

47 GRUPO DE ESTUDIOS CONSTITUCIONALES (1992) p.18.

48 GRUPO DE ESTUDIOS CONSTITUCIONALES (1992) p. 24.

49 GRUPO DE ESTUDIOS CONSTITUCIONALES (1992) p. 25.
} 
$\operatorname{conflictos}^{50}$. Sostenían que con ello se afectaba el principio de igualdad, al imposibilitar el equitativo trato jurisdiccional a los ciudadanos. Frente a esta realidad proponen como deber del Estado crear un servicio judicial que alcance a todos aquellos que por razones económicas, inhibiciones culturales o limitaciones materiales no puedan o les resulte extremadamente difícil acceder a la justicia ${ }^{51}$. Esta propuesta, de manera progresiva, ha sido incorporada a la institucionalidad chilena. El año 1981 la Ley 17.995 crea la Corporación de Asistencia Judicial, servicio público cuya finalidad es «prestar asistencia jurídica y judicial gratuita a personas de escasos recursos» ${ }^{52}$. Posteriormente, la implementación de las reformas procesales en materia penal y laboral han traído consigo la creación de servicios especializados. La Ley 19.718 crea la Defensoría Penal Pública, servicio que proporciona defensa penal a los imputados o acusados que carezcan de abogado. Asimismo, las leyes 20.022 y 20.087 que crean los nuevos juzgados con competencia en materia de trabajo y que establece un nuevo proceso laboral, respectivamente; traen consigo la creación de las Oficinas de Defensa Laboral, entregando defensa laboral a quienes carezcan de medios para ello. Finalmente, a través del mensaje presidencial 496-368 del 3 de enero de 2021 se presenta el proyecto de Ley para la creación de la Defensoría de la Víctima y Servicio Nacional de Acceso a la Justicia.

\subsection{Partidos políticos y sistema electoral}

Un eje central del pensamiento del Grupo de los 24 es la convicción de que los partidos políticos son instrumentos esenciales para la democracia. A ellos corresponde representar a los ciudadanos en la formación de los órganos del Estado, para contribuir a la formación de la voluntad democrática. Así lo manifestaron desde sus inicios en las «Bases Fundamentales de la Reforma Constitucional» de octubre de $1979^{53}$. Plantean que los partidos políticos deben tener libertad para difundir sus doctrinas y programas, para realizar su acción política y propaganda en la forma y condiciones que determine la Constitución y la ley, tal como declararon en el Estatuto de los Partidos Políticos de $1983^{54}$. Esto hoy nos parece evidente, pero en la época en que se propuso implicaba confrontar abiertamente el texto original del artículo $8^{\circ}$ de la Constitución ${ }^{55}$ que prohibía determinadas ideologías políticas y

\footnotetext{
50 GRUPO DE ESTUDIOS CONSTITUCIONALES (1992) p. 23.

51 GRUPO DE ESTUDIOS CONSTITUCIONALES (1992) p. 23.

52 Artículo $2^{\circ}$ Ley 17.995 del 8 de mayo de 1981.

53 Bases Fundamentales de la Reforma Constitucional. GRUPO DE ESTUDIOS CONSTITUCIONALES (1992) p. 49 y sgtes.

54 Artículo $4^{\circ}$ del Estatuto de Partidos Políticos. GRUPO DE ESTUDIOS CONSTITUCIONALES (1992) p. 74.

55 El texto original de la Constitución de 1980 disponía «(t)odo acto de persona o grupo destinado a propagar doctrinas que atenten contra la familia, propugnen la violencia o una concepción de la sociedad, del Estado o del orden jurídico, de carácter totalitario o fundado en la lucha de clases, es ilícito y contrario al ordenamiento
} 
sancionaba a quienes las propugnaban. Dicha disposición se mantendría hasta la reforma constitucional de 1989.

Pero no solo el funcionamiento y libertad de los partidos políticos constituía objeto de preocupación, sino también el sufragio y los sistemas a través de los cuales dicho derecho se ejercía. Por ello en las «Bases para la Reforma Constitucional»sostienen que «los procedimientos electorales deben permitir la representación real de los diversos grupos presentes en la sociedad chilena, porque la capacidad de las instituciones políticas de representar al cuerpo social es condición para alcanzar un efectivo acuerdo democrático de mayorías» ${ }^{56}$. La materialización de este principio resultaba imposible bajo la vigencia de la Ley Orgánica Constitucional 18.700 de Votaciones Populares y Escrutinios de 1989, que, por las modificaciones introducidas por la Ley 18.799 del mismo año consagró el sistema binominal de elecciones ${ }^{57}$. Este planteamiento sólo vendrá a ser incorporado al ordenamiento jurídico chileno a través de la Ley 20.840 del año 2015, que sustituye el sistema binominal por uno proporcional y fortalece la representatividad del Congreso.

institucional de la República. Las organizaciones y los movimientos o partidos políticos que por sus fines o por las actividades de sus adberentes tiendan a esos objetivos, son inconstitucionales. Corresponderá al Tribunal Constitucional conocer de las infracciones a lo dispuesto en los incisos anteriores. Sin perjuicio de las demás sanciones establecidas en la Constitución o en la ley, las personas que incurran o bayan incurrido en las contravenciones señaladas precedentemente no podrán optar a funciones o cargos públicos, sean o no de elección popular, por el término de diez años contado desde la fecha de la resolución del Tribunal. Tampoco podrán ser rectores o directores de establecimientos de educación ni ejercer en ellos funciones de enseñanza, ni explotar un medio de comunicación social o ser directores o administradores del mismo, ni desempeñar en él funciones relacionadas con la emisión o difusión de opiniones o informaciones; ni podrán ser dirigentes de organizaciones políticas o relacionadas con la educación o de carácter vecinal, profesional, empresarial, sindical, estudiantil o gremial en general, durante dicho plazo. Si las personas referidas anteriormente estuvieren a la fecha de la declaración del Tribunal, en posición de un empleo o cargo público, sea 0 no de elección popular, lo perderán, además, de pleno derecho. Las personas sancionadas en virtud de este precepto, no podrán ser objeto de rehabilitación durante el plazo señalado en el inciso cuarto. La duración de las inhabilidades contempladas en este artículo se elevará al doble en caso de reincidencia».

56 Bases Fundamentales de la Reforma Constitucional. GRUPO DE ESTUDIOS CONSTITUCIONALES (1992) p. 47.

57 El texto modificado de la Ley 18.700 es el siguiente: «artículo 109 bis.- En caso de elecciones de Parlamentarios, el Tribunal proclamará elegidos Senadores o Diputados a los dos candidatos de una misma lista, cuando ésta alcanzare el mayor número de sufragios y tuviere un total de votos que excediere el doble de los que alcanzare la lista o nómina que le siguiere en número de sufragios.

Si alguna lista obtuviere los dos cargos, elegirá un cargo cada una de las listas o nóminas que obtengan las dos más altas mayorías de votos totales de lista o nómina, debiendo el Tribunal proclamar elegidos Senadores o Diputados a aquellos candidatos que, dentro de cada lista o nómina, hubieren obtenido las más altas mayorías.

Si el segundo cargo por llenar correspondiere con igual derecho a dos o más listas o nóminas, el Tribunal proclamará electo al candidato que hubiere reunido mayor cantidad de preferencias individuales.

En caso de empate entre candidatos de una misma lista o entre candidatos de distintas listas o nóminas, que a su vez estuviesen empatadas, el Tribunal procederá, en audiencia pública, a efectuar un sorteo entre ellos, y proclamará electo al que salga favorecido. 
Finalmente, la propuesta sostenida por el grupo relativa a la votación de chilenos en el extranjero ${ }^{58}$ sólo se concretará por Ley de reforma constitucional 20.748 de 2014, que posibilitó el sufragio de chilenos en el extranjero en elecciones presidenciales y plebiscitos nacionales.

\subsection{Tribunal Constitucional}

La legitimidad de la justicia constitucional era una de las preocupaciones del Grupo de los 24. Proponían que el Tribunal Constitucional modificara su integración aumentando su legitimidad democrática, generando una integración por tercios con origen en los tres poderes del Estado ${ }^{59}$ reemplazando de esta forma la integración original de la Constitución de 1980, en cuyo nombramiento participaban las Fuerzas Armadas y se caracterizaba por su déficit democrático ${ }^{60}$. Asimismo, proponían modificar sus competencias estableciendo la declaración de inconstitucionalidad de una Ley cuando ésta hubiera sido declarada inaplicable al menos en tres oportunidades por la Corte Suprema ${ }^{61}$. Ambas propuestas fueron recogidas por la reforma constitucional de $2005^{62}$, que modificó la integración del tribunal. Este ahora se conforma por diez ministros, tres designados por el Presidente de la República, cuatro elegidos por el Congreso Nacional, y tres elegidos por la Corte Suprema. Además, incorporó la facultad para declarar inconstitucional un precepto legal por las cuatro quintas partes de sus miembros cuando dicho precepto haya sido declarado inaplicable anteriormente por el propio tribunal.

\subsection{Otras propuestas incorporadas al ordenamiento jurídico chileno}

El Grupo de los 24 formuló propuestas en diversas materias. Entre otras, se concretaron en reformas legales y constitucionales las siguientes:

a) Derecho, sin discriminación alguna, a igual salario por igual trabajo ${ }^{63}$, incorporado por la Ley 20.348 de 2009 que agrega el artículo 62 bis al Código del Trabajo, consagrando la obligación para el empleador de dar

\footnotetext{
58 Esta propuesta fue planteada por el grupo en artículo 131 del Proyecto de Ciudadanía, Inscripciones y Sistema electoral GRUPO DE ESTUDIOS CONSTITUCIONALES (1992) p. 191.

59 Proyecto relativo a la «Organización y Funcionamiento del Poder Judicial», GRUPO DE ESTUDIOS CONSTITUCIONALES (1992) p. 35

${ }_{60}$ Sobre las sucesivas modificaciones del Tribunal Constitucional en Chile se puede revisar su página web en https://www.tribunalconstitucional.cl/tribunal/historia

${ }_{61}$ Proyecto relativo a la «Organización y Funcionamiento del Poder Judicial», GRUPO DE ESTUDIOS CONSTITUCIONALES (1992) p. 34.

62 Ley de reforma constitucional $\mathrm{N}^{\circ} 20.050$.

63
}

(C) UNED. Revista de Derecho Politico

N. ${ }^{o} 112$, septiembre-diciembre 2021, págs. 355-382 
cumplimiento al principio de igualdad de remuneraciones entre hombres y mujeres que presten un mismo trabajo.

b) Terminar con toda discriminación en contra de los hijos en razón de la existencia de matrimonio entre sus padres ${ }^{64}$. Esta propuesta fue incorporada mediante la Ley 19.585 de 1998, que eliminó las distinciones jurídicas de los hijos derivadas de la filiación.

c) Propone la consagración del divorcio vincular ${ }^{65}$, introducido en Chile recién en el año 2004, por la Ley 19.947.

d) En materia de Derecho Internacional de los Derechos Humanos, proponen incorporar al derecho interno la garantía de todos los derechos y libertades reconocidos en la Declaración Universal de Derechos Humanos y pactos complementarios ratificados por Chile ${ }^{66}$. Esto se materializó por la reforma 18.825 del año 1989, que agregó al artículo 5 inciso $2^{\circ}$ de la Constitución el deber de los órganos del Estado de respetar y promover no sólo los derechos establecidos en la Constitución, sino también por los tratados internacionales ratificados por Chile y que se encuentren vigentes.

e) En materia el proceso de generación de un nuevo texto constitucional, el Grupo propuso que el estudio del proyecto constitucional se debería realizar a través de una asamblea constituyente ${ }^{67}$. Esta propuesta se incorporó por la Ley de reforma constitucional 21.200, del año 2019, que materializó el «Acuerdo por la Paz y la Nueva Constitución», al que llegaron distintos partidos políticos con fecha 15 de noviembre de 2019, en el contexto de las movilizaciones sociales iniciadas el 18 de octubre del mismo año. Se estableció que para la elaboración de un nuevo texto constitucional se convocaría a plebiscito para el 26 de abril de 2020, (que, en atención a las condiciones sanitarias se realizó el 25 de octubre de 2020). Se consultó a la ciudadanía si «Aprueba» o «Rechaza» elaborar una nueva Constitución y el tipo de órgano encargado de redactarla: «Convención Mixta Constitucional», integrada por parlamentarios y miembros elegidos por votación popular o una asamblea constituyente denominada «Convención Constitucional», integrada en su totalidad por personas electas por sufragio universal. Finalmente, este texto deberá ser refrendado por la ciudadanía en un plebiscito.

64 Proposiciones de la Subcomisión de Legislación de la Mujer. GRUPO DE ESTUDIOS CONSTITUCIONALES (1992) p.299.

65 Proposiciones de la Subcomisión de Legislación de la Mujer. GRUPO DE ESTUDIOS CONSTITUCIONALES (1992) p.299.

66 GRUPO DE ESTUDIOS CONSTITUCIONALES (1992) p.65.

67 GRUPO DE ESTUDIOS CONSTITUCIONALES (1992) p.66. 
Como hemos visto, el trabajo de resistencia al proyecto constitucional autoritario tuvo concreción en las sucesivas reformas a la Constitución de 1980 y el abandono progresivo de la democracia tutelada, así como la implementación de instituciones que reforzaron la protección de derechos fundamentales y profundizaron el Estado de Derecho.

La resistencia constitucional del Grupo de los 24 actuó como una reserva de valores democráticos y republicanos. Frente al intento de modificar las bases mismas del fundamento del poder político ${ }^{68}$, pensó, conservó, transmitió, y enseñó las instituciones y el ejercicio del poder público, en base a conceptos como la soberanía popular, el respeto a los derechos fundamentales, la política como parte de la naturaleza humana y la importancia de los partidos políticos como su concreción institucional necesaria, entre otras. Hoy estas cuestiones no son controvertidas, pero durante el paréntesis autoritario fueron puestas en duda, y la adhesión a estos principios, ante la opinión pública y en el aula, representaba un riesgo real.

No sólo en sus documentos, sino en su labor política y académica, el trabajo de sus integrantes se transformaría en la base de las reformas al proyecto original de la dictadura el año 1989, pero también durante los 90, la reforma de 2005 e incluso, de las instituciones que hoy se proponen como necesarias para un nuevo pacto fundamental de convivencia política. Es importante además destacar que fueron los formadores de la generación de profesores y profesoras de Derecho Constitucional que han trabajado en las últimas décadas para impulsar la demanda de una nueva Constitución.

\section{PROPUESTAS PARA UNA NUEVA CONSTITUCIÓN Y EL IDEARIO DEL GRUPO DE ESTUDIOS CONSTITUCIONALES}

Las reformas a la Constitución de 1980 fueron insuficientes para superar el problema constitucional. Las etapas de la búsqueda institucional del cambio constitucional y de activación del poder constituyente originario así lo demostraron. Muchos de los contenidos constitucionales que hoy son objeto de discusión académica y política, aunque con otro lenguaje, son reconducibles también a propuestas del Grupo de los 24. En este apartado, las propuestas del Grupo serán clasificadas en materias, para luego señalar cómo se han recogido por la academia ${ }^{69}$ y los documentos elaborados por centros de estudios y partidos políticos con miras a su implementación en una nueva Constitución.

68 Ver Palma (2007) sobre los discursos legitimadores de la Constitución de 1980 durante los inicios de su vigencia.

69 La literatura publicada sobre el cambio constitucional en Chile,especialmente durante la última década, es prácticamente inabordable. Nos hemos concentrado principalmente en revisar los libros y los documentos políticos más relevantes que tienen por objeto presentar propuestas para la nueva Constitución. Esto deja muchos textos fuera, pero la extensión del trabajo no permite una bibliografía tan extensa.

(C) UNED. Revista de Derecho Politico

N. ${ }^{\circ} 112$, septiembre-diciembre 2021, págs. 355-382 


\subsection{Rol del Estado, Estado social y democrático de derecho y derechos sociales}

En materia del rol del Estado en la economía, el Grupo de los 24 rechaza la opción de la Constitución por un modelo económico específico, afirmando que «[l]as normas de rango constitucional en lo económico-social deben ser lo suficientemente amplias y flexibles como para hacer posible la aplicación de diversos esquemas económicos» ${ }^{70}$. No obstante, la idea del consenso sobre esta materia parece esencial puesto que expresan «es igualmente necesario buscar el mayor acuerdo posible de alcanzar sobre cuál ha de ser la función del Estado en el orden económico-social, cuál el régimen de la propiedad y el de las empresas y cuáles las bases esenciales del sistema económico» ${ }^{71}$.

El Grupo era consciente de que «las decisiones en materia económico-social son esencialmente de carácter político» ${ }^{72}$ y no técnico. Así, proponían en su documento «Bases Constitucionales de Orden Económico» como principio general que se reconociera la importancia del Estado como un activo promotor del desarrollo nacional, y la necesidad de «evitar la concentración excesiva del poder económico pues significa una amenaza a la vigencia real de las libertades democráticas» ${ }^{73}$. Propone establecer que la comunidad chilena debiera reconocer «como objetivos económico-sociales fundamentales la plena satisfacción de las necesidades básicas de todos sus miembros, propender a un mayor bienestar colectivo y a una distribución más justa de la riqueza y del ingreso ${ }^{74}$. Señalaban que la organización económica debía fomentar el pleno desarrollo de la iniciativa y creatividad individual y social. Consideraban que el mercado era eficaz para asignar los recursos, pero entendían que debía combinarse con la planificación estatal para atender las necesidades colectivas, y promover una mejor distribución de la riqueza y del ingreso. Proponían una «democracia económica [que] implica una activa participación del pueblo, y en particular de los trabajadores, a través de mecanismos adecuados, en los procesos de planificación y en formulación y evaluación de la estrategia nacional de desarrollo» ${ }^{75}$.

En materia de derechos sociales, destaca el artículo 17 de su «Acta de Derechos Humanos» que dispone «La satisfacción de los derechos económicos, sociales y culturales, indispensables a la dignidad y libre desarrollo de la personalidad, es un derecho de todo miembro de la sociedad chilena. Toda persona tiene derecho a un nivel de vida adecuado que le asegure, así como a su familia, la salud, la educación, y el bienestar, y en especial la alimentación suficiente, el vestuario, la vivienda, la asistencia médica y los servicios sociales necesarios para cubrir sus necesidades básicas. Toda persona quedará especialmente protegida contra el hambre y la miseria. El Estado adoptará todas las políticas y medidas nacionales e internacionales necesarias,

\footnotetext{
70 GRUPO DE ESTUDIOS CONSTITUCIONALES (1992) p. 61

71 GRUPO DE ESTUDIOS CONSTITUCIONALES (1992) P. 9

72 GRUPO DE ESTUDIOS CONSTITUCIONALES (1992) P. 40

73 GRUPO DE ESTUDIOS CONSTITUCIONALES (1992) p. 42

74 GRUPO DE ESTUDIOS CONSTITUCIONALES (1992) p.. 41

75 GRUPO DE ESTUDIOS CONSTITUCIONALES (1992) P. 7
} 
especialmente económicas y técnicas, y hasta el máximo de los recursos de que disponga, para lograr progresivamente la plena efectividad de los derechos económicos, sociales y culturales. Los chilenos tienen derecho a organizarse para requerir el cumplimiento de este mandato ${ }^{76}$. Particularmente interesantes son las referencias a derechos como la recreación, a la salud mental y a la cultura, que serán reconocidos más adelante en constituciones del nuevo constitucionalismo latinoamericano.

Más aún, indican que debe establecerse a nivel constitucional que «toda persona tiene derecho a un nivel de vida adecuado que le asegure, así como a su familia, la salud, la educación y el bienestar, y en especial, la alimentación suficiente, el vestuario, la vivienda, la asistencia médica y los servicios sociales necesarios para cubrir las necesidades básicas ${ }^{77}$. Esto se puede vincular con la discusión actual sobre el derecho al Ingreso Básico Universal o Renta Básica Universal, que ha sido propuesto como uno de los contenidos de la nueva Constitución ${ }^{78}$.

En lo que se refiere a derechos sociales, la Constitución de 1980 rehuyó los aportes del constitucionalismo social, negándose al reconocimiento de los mismos, como el derecho al trabajo, a huelga, educación, salud, seguridad social, y otros; reconvirtiéndolos en libertades. Los pocos que sí se consagran como derechos encuentran una regulación constitucional que garantiza la participación de los privados entregando la provisión de estos bienes públicos a las lógicas del mercado. Este punto es de la máxima relevancia, ya que nuestra lectura es que, aunque el proceso constituyente en Chile se inicia mucho antes de octubre de 2019, el despliegue del itinerario de cambio constitucional es consecuencia de una demanda por Estado social, por un cambio de paradigma en relación con el rol del Estado, y por la satisfacción de bienes públicos cuya traducción jurídico-constitucional son los derechos sociales.

Las ideas formuladas por el Grupo en estas materias continúan vigentes y se encuentran en el centro de la discusión constitucional actual. Así, la propuesta del Grupo de «establecer una Democracia Social» ${ }^{79}$ es recogida por gran parte de la doctrina constitucional partidaria de un cambio constitucional. Por establecer una fórmula de Estado social y democrático de Derecho se han manifestado autores como Aguilar, Oñate, Ruiz-Tagle, Viera y Zúñiga ${ }^{80}$, entre muchos otros, además de ser una

76 GRUPO DE ESTUDIOS CONSTITUCIONALES (1992) p. 278. Esta disposición recuerda las garantías «desde abajo» de los derechos sociales a las que hace referencia Gerardo Pisarello.

77 Artículo 17 del proyecto de Acta de Derecho Humanos. GRUPO DE ESTUDIOS CONSTITUCIONALES (1992) p. 278.

78 ZUÑIGA FAJURI, Alejandra (2021). «El ingreso básico universal en la nueva Constitución chilena» en Asociación Chilena de Derecho Constitucional «Tránsito Constitucional. Camino hacia una nueva Constitución, Valencia, Tirant lo Blanch (2021), p. 269

79 GRUPO DE ESTUDIOS CONSTITUCIONALES (1992) P. 9

80 AGUILAR CAVALLO, Gonzalo (2015) «Modelo económico y nueva Constitución: el estatuto constitucional de la propiedad desde un enfoque de derechos». En: Chía Eduardo y Quezada, Flavio (editores) Propuestas para una nueva Constitución (originada en democracia), Santiago, Instituto Igualdad, Facultad de Derecho Universidad de Chile, Friedrich Ebert-Stiftung, p. 144; OÑATE VERA, Emilio (2021). «Hacia un Estado social y democrático de Derecho» en CENTRO DE ESTUDIOS 
idea recogida en los documentos vinculados a centros de pensamiento de diversos partidos políticos ${ }^{81}$.

\subsection{Igualdad sustantiva y grupos desaventajados}

El Grupo de los 24 parece reconocer un principio de igualdad sustantiva al proponer que «[e]s misión del Estado remover los obstáculos de orden económico y social que, limitando de hecho la libertad y la igualdad de los ciudadanos, impidan el pleno desenvolvimiento de la personalidad humana y la efectiva participación de éstos en la organización política, económica y social del país» y agregan una propuesta que bien puede entenderse como la constitucionalización de las acciones afirmativas cuando sostienen que «las normas y acciones de apoyo y estímulo, que con tales fines puedan acordarse, se entienden complementarias del principio general de igualdad ante la ley» ${ }^{82}$.

Esto es de la mayor relevancia, ya que una de las demandas actuales es superar el concepto de igualdad puramente formal que establece la Constitución de 1980 y avanzar hacia un principio de igualdad que proscriba la discriminación y mandate al legislador para establecer políticas públicas que corrijan la desventaja estructural que sufren algunos grupos sociales para el efectivo ejercicio de sus derechos ${ }^{83}$.

En relación a las mujeres, destacan sus propuestas de la consagración de los principios de igualdad salarial y el principio de paternidad responsable, contemplado en las «Proposiciones de la subcomisión de legislación de la mujer» ${ }^{84}$. La dimensión constitucional de la situación de desventaja estructural de las mujeres ha sido planteada también desde la academia ${ }^{85}$. Específicamente, el año 2020 un grupo de profesoras de Derecho Público presentaron a la discusión pública un documento con propuestas para una Constitución con perspectiva de género. En este se plantea la

PEDRO AGUIRRE CERDA (2021) «Propuestas radicales para una nueva Constitución. Parte I» Disponible en: https://www.flipsnack.com/PEDROAGUIRRECERDA/libro-propuestas-radicales-para-una-nueva-constituci-n.html; RUIZ-TAGLE, Pablo (2016) Cinco Repúblicas y una tradición, Santiago, LOM, p 244 y ss; VIERA ÁLVAREZ, Christian (2019). «Estado Social como fórmula en la Constitución que queremos" Bassa, Jaime; Ferrada, Juan Carlos y Viera, Christian (editores) La Constitución que queremos, Santiago, LOM, p 107.; ZUÑIGA URBINA Francisco (2021). «Constitución: El Estado Social y las cláusulas económicas y sociales» en Asociación Chilena de Derecho Constitucional «Tránsito Constitucional. Camino hacia una nueva Constitución», Valencia, Tirant lo Blanch.

81 PARTIDO POR LA DEMOCRACIA (2020); Zuñiga Urbina, Francisco y Peroti Díaz, Felipe (2020). Bases y Fundamentos de una Propuesta Constitucional Progresista, documento electrónico disponible en https://institutoigualdad.cl/2020/11/26/bases-y-fundamentos-de-una-propuesta-constitucional-progresista/; Cifuentes Ovalle, Javier y Pérez Lillo, Claudio (editores) (2021). Diálogos Constitucionales: Contenidos para un nuevo Pacto Social en Chile, Santiago, Centro de Estudios del Desarrollo, Konrad Adenauer Stiftung; CENTRO DE ESTUDIOS PEDRO AGUIRRE CERDA (2021).

82 GRUPO DE ESTUDIOS CONSTITUCIONALES (1992) P. 42

83 CODDOU (2019); ESPARZA (2021a); ESPARZA (2021b)

84 GRUPO DE ESTUDIOS CONSTITUCIONALES (1992) p. 290.

85 ZÚÑIGA y PONCE DE LEÓN (2020) 
incorporación constitucional de la corresponsabilidad parental y la reproducción como una responsabilidad social ${ }^{86}$.

En cuanto al reconocimiento constitucional de Pueblos Originarios, el Grupo propuso en su «Acta de Derechos Humanos», artículo 27, que «Las minorías étnicas tiene derecho al respeto y a la promoción de su identidad étnica, cultural, lingüística y religiosa, sin discriminación alguna. El Estado debe adoptar medidas eficaces con el objeto de prevenir y eliminar toda discriminación, publicidad u otra actividad que amenace o pueda amenazar la existencia de estas minorías o que obstaculicen su derecho a expresar y desarrollar sus propias características. El Estado debe crear los mecanismos necesarios para garantizar a estas minorías la preservación de los elementos esenciales que forman parte de su identidad tales como la tierra, su lenguaje, y sus formas de organización económica y social. Asimismo, deberá establecer las instancias adecuadas para su participación como grupo étnico en la resolución de los problemas que les atañen, y sus miembros gozarán de iguales derechos y deberes que los demás integrantes de la comunidad nacional de la que forman parte». De esta forma se adelantaron en reconocer una deuda que no se ha saldado desde el retorno a la democracia. Hoy es ampliamente reconocida, aunque sea discutido el modo en que se debe abordar a los pueblos originarios y el multiculturalismo en la Constitución, que va desde un mero reconocimiento al establecimiento de un Estado plurinacional ${ }^{87}$.

En materia de infancia destaca el artículo 11 del mismo documento que dispone «Ningún niño deberá ser objeto de discriminación derivada de su nacimiento ni de la condición legal u otra de cualquier especie de sus padres, y tendrá derecho a protección por parte de su familia, del Estado y de la sociedad» ${ }^{88}$. Hasta hoy la Constitución de 1980 no hace referencia ninguna a los niños, niñas o adolescentes como sujetos de derecho ni establece un mandato de protección de la infancia, como aquí se proponía. La necesidad de la incorporación de la infancia dentro de las materias de la nueva Constitución ha sido destacada por la doctrina ${ }^{89}$.

\subsection{Necesidad de modificar la forma de gobierno, señalando dos alternativas posibles, la consagración de un régimen presidencial atenuado, o el establecimiento de un sistema semipresidencial de gobierno90}

En su proyecto «Bases Fundamentales de la Reforma Constitucional» señalaban «Estamos de acuerdo en que, dentro de la tradición presidencial de la democracia chilena, deben establecerse reglas que faciliten la formación de mayorías estables de

\footnotetext{
86 Disponible en: https://www.uchile.cl/documentos/nueva-constitucion-con-perspectiva-de-genero_169952_0_3515.pdf

87 AYLWIN (2020); GAJARDO (2016); VILLAVICENCIO (2019).

88 GRUPO DE ESTUDIOS CONSTITUCIONALES (1992) p. 277.

89 ÁLVEZ Y ZAWADZKY (2017).

90 GRUPO DE ESTUDIOS CONSTITUCIONALES (1992) P. 53-54
} 
Gobierno» ${ }^{91}$ pero los integrantes del Grupo no pudieron ponerse de acuerdo en una sola fórmula. Llama la atención que aún hoy los críticos de la Constitución de 1980 no han llegado a tener una posición unánime en este sentido. En el programa constitucional del segundo gobierno de Michelle Bachelet no hubo acuerdo ${ }^{92}$. El documento «Bases constitucionales para una propuesta progresista» ${ }^{93}$ que recoge acuerdos de diversos académicos pertenecientes a la alianza de centro izquierda Convergencia Progresista, parece tomar partido por la opción del sistema semipresidencial de gobierno, lo mismo las publicaciones del Centro de Estudios del Desarrollo, vinculado a la Democracia Cristiana ${ }^{94}$. También diversos autores se han pronunciado por este régimen como una propuesta para la nueva Constitución ${ }^{95}$, como otros se mantienen en la línea de un sistema presidencial atenuado ${ }^{96}{ }^{97}$ o parlamentarizado, como aparece en el documento de propuestas constitucionales del Partido por la Democracia.

\section{4.. Descentralización y Estado Regional}

En su proyecto «Estatuto de Regionalización» el Grupo propuso que se modificara la forma de Estado hacia un Estado unitario descentralizado políticamente ${ }^{98}$. Proponían que las regiones fueran «organizaciones políticas territoriales, dotadas de personalidad jurídica de derecho público que gozan de autonomía, la que se expresa a través de órganos normativos de gobierno y administración propios», que contaran con patrimonio propio y autonomía financiera coordinada con las finanzas del Gobierno Central del Estado y de las Comunas ${ }^{99}$.

La necesidad de avanzar hacia una descentralización política es una cuestión que ha sido ampliamente reconocida por todos los sectores ${ }^{100}$. La incorporación a nivel constitucional del principio de solidaridad regional, también propuesta del Grupo

91 GRUPO DE ESTUDIOS CONSTITUCIONALES (1992) P. 53

92 En efecto en el documento Bases de la Nueva Constitución para Chile, Primer Informe; se recogen en el capítulo de régimen político las posibilidades de un régimen presidencial flexible y un régimen semipresidencial como propuestas alternativas. ZUÑIGA (2014) anexo p. 289 y sgtes.

93 ZUÑIGA URBINA, Francisco y PEROTI DÍAZ, Felipe (2020). Bases y Fundamentos de una Propuesta Constitucional Progresista, documento electrónico disponible en https://institutoigualdad. cl/2020/11/26/bases-y-fundamentos-de-una-propuesta-constitucional-progresista/p. 58 y sgtes.

94 CIFUENTES OVALLE, Javier y PÉREZ LILLO, Claudio (editores) (2021) Diálogos Constitucionales: Contenidos para un nuevo Pacto Social en Chile, Santiago, Centro de Estudios del Desarrollo, Konrad Adenauer Stiftung

95 NOGUEIRA (2021); SIERRA (2015) p. 389; ESCUDERO (2021).

96 MELENDEZ (2021); PARTIDO POR LA DEMOCRACIA (2020).

97 Ver listado de propuestas en materia de forma de Estado de diversos académicos en SIERRA (2016) p.172.

98 GRUPO DE ESTUDIOS CONSTITUCIONALES (1992) p. 101.

99 GRUPO DE ESTUDIOS CONSTITUCIONALES (1992) p. 102.

100 Ver Informe de COMISIÓN ASESORA PRESIDENCIAL EN DESCENTRALIZACIÓN Y DESARROLLO REGIONAL de 2014. 
que se concretó en la reforma constitucional del 2005, no ha significado en la práctica una disminución de la dimensión territorial de la desigualdad. Aunque hay avances en materia de democratización de las autoridades políticas regionales, este es uno de los temas en que hay consenso, discutiéndose en torno a avanzar hacia una forma de Estado regional o semifederal ${ }^{101}$.

\subsection{Aumento de la legitimidad democrática de la jurisdicción constitucional y modificación de sus atribuciones}

Ya se ha explicado esto en el apartado anterior. Pero es importante señalar que la organización de la jurisdicción constitucional en la nueva carta es uno de los temas relevantes en la discusión constitucional actual, existiendo consenso en que debe modificarse la forma de nombramiento de los ministros y eliminación del control preventivo de constitucionalidad de la ley, y en general, una disminución de las atribuciones del Tribunal Constitucional que hoy se consideran hipertrofiadas ${ }^{102}$.

\subsection{Cláusula de recepción del Derecho Internacional de los Derechos Humanos}

El Grupo sostuvo la necesidad de el establecimiento de «una disposición de carácter general mediante la cual se considere como parte integrante del orden jurídico nacional los principios y normas contenidos en la Declaración Universal de los Derechos Humanos, en el Pacto de Derechos Civiles y Políticos, y en el Pacto Internacional de Derechos Económicos y Sociales, así como cualquier otro instrumento sobre la materia que Chile ratifique en el futuro» ${ }^{103}$.

Aunque esta propuesta dio lugar a la reforma del artículo quinto inciso segundo ya explicada, la solución no estableció una jerarquía clara de estos instrumentos en nuestro sistema de fuentes. Esto ha dado lugar a numerosas discusiones doctrinales y tiene relevancia decisiva en la resolución de causas en tribunales y en otras sedes. Una de las cuestiones a tratar en la Convención Constitucional sin duda será este problema que se ha planteado por la doctrina ${ }^{104}$.

101 SZMULEWICZ (2021); Szmulewicz y Precht (2021); HENRÍQUEZ (2021) PAREDES (2019). Ver listado de propuestas en materia de forma de Estado de diversos académicos en SIERRA (2016) p.125.

${ }_{102}$ AHUMADA Paula (2018) «El Tribunal Constitucional en Chile: Tres ensayos de justicia constitucional». En Huneeus, Carlos y Avendaño, Octavio (editores): El sistema político de Chile, Santiago, LOM; BORDALÍ SALAMANCA, Andrés (2015). «Una nueva justicia constitucional para una nueva Constitución chilena». En: Chía Eduardo y Quezada, Flavio (editores) Propuestas para una nueva Constitución (originada en democracia), Santiago, Instituto Igualdad, Facultad de Derecho Universidad de Chile, Friedrich Ebert-Stiftung; BUSCH (2021); PAREDES (2020); ZUÑIGA y PEROTI (2020).

103 GRUPO DE ESTUDIOS CONSTITUCIONALES (1992) p. 65.

104 Aguilar Cavallo, Gonzalo (2021) «Sistema de fuentes y Derecho Internacional de los Derechos Humanos en la Nueva Constitución» en Asociación Chilena de Derecho Constitucional «Tránsito 


\subsection{Necesidad de modificar el estatuto constitucional de las Fuerzas Armadas y reforzar su subordinación al poder civil}

El grupo demostró firmeza y coraje cuando en plena dictadura sostuvo que en las Fuerzas Armadas deben «obediencia al régimen democrático y sus autoridades civiles libremente elegidas por la comunidad política. Se trata entonces de Fuerzas Armadas profesionales, no deliberantes, disciplinadas y por entero ajenas a las contingencias políticas, dedicadas a su función propia, de garantizar la defensa nacional» ${ }^{105}$.

Aunque las reformas constitucionales de la transición eliminaron el carácter de garantes de la institucionalidad y otras disposiciones sobre la materia, la efectiva subordinación y particularmente el cumplimiento de la obligación de no deliberación de las Fuerzas Armadas y de orden y Seguridad es una asignatura pendiente de la democracia chilena. Recién en los últimos años se ha comenzado a relevar por la doctrina la necesidad de revisar la regulación constitucional de estos órganos del Estado y reforzar su carácter subordinado al poder civil y su obligación de no intervenir en la deliberación política ${ }^{106}$.

Quedan fuera de este análisis algunas otras materias que, por una cuestión de extensión, no analizaremos pero que fueron discutidas por el Grupo de los 24 y que tienen espacio todavía en el debate actual. A modo simplemente ejemplar: la organización del Congreso Nacional como bicameral o unicameral, desafíos en materia de independencia judicial, reformulación de la función social de la propiedad, medioambiente y utilización racional de recursos naturales y modelos de desarrollo económicos que protegan el equilibrio ecológico, regulación restrictiva de los regímenes de excepción constitucional, organización municipal y poder político local.

\section{CONCLUSIONES}

En el desarrollo de este trabajo vinculamos el trabajo del Grupo de Estudios Constitucionales con la discusión sobre contenidos dentro del proceso constituyente actual. Del trabajo realizado concluimos lo siguiente:

Constitucional. Camino hacia una nueva Constitución», Valencia, Tirant lo Blanch; Núñez Donald, Constanza (2018) «Apertura constitucional al Derecho Internacional de los Derechos Humanos en una nueva Constitución» Revista Ius Et Praxis, 24(3).

105 GRUPO DE ESTUDIOS CONSTITUCIONALES (1992) p. 14.

106 CONTRERAS, Pablo y SALAZAR, Sebastián (2021). «Las Fuerzas Armadas y de Orden y Seguridad en la Nueva Constitución» en Asociación Chilena de Derecho Constitucional «Tránsito Constitucional. Camino hacia una nueva Constitución», Valencia, Tirant lo Blanch; SILVA MENA, Anamaría, y MONTERO ALLENDE, Ricardo (2021). «Seguridad y Nueva Constitución: Una oportunidad para cambiar la mirada» en CIFUENTES OVALLE, Javier y PÉREZ LILLO, Claudio (editores) Diálogos Constitucionales: Contenidos para un nuevo Pacto Social en Chile, Santiago, Centro de Estudios del Desarrollo, Konrad Adenauer Stiftung. 
- El proceso constituyente chileno es un continuo, en que la demanda por el cambio de la Constitución de 1980 se inicia al mismo tiempo que ésta se elabora. Para demostrar esta continuidad dividimos el proceso constituyente en cuatro etapas. La etapa de la resistencia; la etapa de la resignación, la etapa de la búsqueda institucional de cambio constitucional y la etapa de la activación del poder constituyente originario.

- La etapa de la resistencia fue obra principal, aunque no exclusiva, del trabajo del Grupo de los 24, cuyo trabajo va a ser incorporado en las sucesivas reformas que tuvieron lugar durante la etapa de la resignación. Esto se demuestra en las numerosas reformas constitucionales y legales que tienen origen en las propuestas del grupo.

- La labor del Grupo de los 24 durante el paréntesis autoritario sirvió como nexo entre las etapas de las repúblicas o la evolución constitucional democrática en Chile. Tanto sus propuestas y documentos como colectivo, como la labor académica y docente de alguno de sus integrantes, dieron lugar a una nueva generación de cultores del derecho constitucional que, aunque sin estar conscientes de ello, continuaron con las demandas de profundización de la democracia, recuperación de los aportes del constitucionalismo social y mantuvieron viva la demanda por una nueva Constitución en Chile, dando lugar al proceso de cambio constitucional que hoy vivimos.

- Muchos de los elementos que hoy se discuten en el debate constitucional actual pueden reconducirse a propuestas formuladas durante la década de los 80 por el grupo. Hoy éstas son postuladas tanto por académicos emergentes como por centros de pensamiento o actores políticos.

- Finalmente, lo anterior permite afirmar que existe una suerte de genealogía del constitucionalismo democrático actual que se remonta al Grupo de los 24, mirado como colectivo.

Title:

Genealogy of democratic constitutionalism in Chile: the work of the Group of 24 on proposals for constitutional change

\section{Summary:}

1. Introduction. - 2. A proposal for the periodification of the Chilean constituent process. -3 . he Constitutional Studies Group and its main 
ideas. - 4. Ideas of the Group of 24 included in legislative or constitutional changes during the validity of the 1980's Constitution. - 4.1. Modernization of the Judiciary and administration of justice. - 4.2. Political parties and electoral system. - 4.3. Constitutional Court. - 4.4. Other proposals incorporated at the Chilean legal system. -5 . Proposals for a new Constitution and the ideology of the Constitutional Studies Group. 5.1. Role of the State, social and democratic State of law and social rights. - 5.2. Substantive equality and disadvantaged groups. - 5.3. Need to modify the form of government, pointing out two possible alternatives, the consecration of a attenuated presidential regime, or the establishment of a semi-presidential system of government. - 5.4. Decentralization and Regional State. - 5.5. Increasing the democratic legitimacy of constitutional jurisdiction and modifying its powers. - 5.6. Clause of reception of the International Law of the Human Rights. - 5.7. The need to modify constitutional status of the Armed Forces and strengthen their subordination to civilian power. -6 . Conclusions.

\title{
Resumen:
}

El presente trabajo pretende rescatar el trabajo del Grupo de Estudios Constitucionales, sosteniendo que conservó la tradición constitucional demócrata durante el paréntesis autoritario. Se demuestra que los contenidos propuestos hoy en el debate constitucional en muchas materias son reconducibles a las propuestas del Grupo, y que, por lo tanto, existe una continuidad entre sus propuestas y el desarrollo del constitucionalismo democrático y el desarrollo del proceso constituyente hasta nuestros días.

\begin{abstract}
:
The present work tries to rescue the work of the Group of Constitutional Studies, maintaining that it conserved the democratic constitutional tradition during the authoritarian parenthesis. It is shown that the contents proposed today in the constitutional debate in many matters are traceable to the Group's proposals, and that, therefore, there is continuity between its proposals and the development of democratic constitutionalism and the development of the constituent process to this day.
\end{abstract}

\section{Palabras claves:}

Proceso Constituyente Chileno - Grupo de Estudios Constitucionales Grupo de los 24 .

\section{Keywords:}

Chilean Constituent Process - Constitutional Studies Group - Group of 24. 